\title{
The Inhibitory Effect of Diethanolamine on Corrosion of Mild Steel in 0.5 M Sulphuric Acidic Medium
}

\author{
M. Ramananda Singh, Kalpana Bhrara and Gurmeet Singh* \\ Department of Chemistry, University of Delhi, Delhi-110007, India
}

Received 2 April 2008; accepted 2 October 2008

\begin{abstract}
The inhibitory effect of diethanolamine (DEA) on corrosion of mild steel in $0.5 \mathrm{M}$ $\mathrm{H}_{2} \mathrm{SO}_{4}$ was investigated by various corrosion monitoring techniques. Galvanostatic polarization study revealed that this compound is a very good inhibitor. The inhibition efficiency (I\%) varies in the range of $88.7 \%$ to $55.3 \%$ for a concentration range of $10^{-3}$ $\mathrm{M}$ to $10^{-7} \mathrm{M}$ at $303 \mathrm{~K}$, respectively. A study of corrosion potential $\left(\mathrm{E}_{\text {corr }}\right)$ reveals that DEA is a mixed type inhibitor. DEA inhibited mild steel corrosion due to physical adsorption of the inhibitor on the metal surface. The study at higher temperatures indicates that the inhibition efficiency decreases with the increase in temperature. The adsorption of DEA on the mild steel surface in $0.5 \mathrm{M} \mathrm{H}_{2} \mathrm{SO}_{4}$ follows the Frumkin's adsorption isotherm. The results of potentiostatic polarization study revealed that DEA is a strong passivating additive. The results of infra red (IR) spectroscopy, scanning electron microscopy (SEM) and quantum chemical study supplement the results of the electrochemical techniques.
\end{abstract}

Keywords: corrosion inhibitions, inhibitor, diethanolamine, sulphuric acid, galvanostatic polarization, potentiostatic polarization, IR spectroscopy, scanning electron microscopy and quantum chemical calculation.

\section{Introduction}

The investigation of inhibition of corrosion of iron is a matter of high theoretical as well as practical interest [1]. Acids are widely used in many industries. Some of the important areas of application are industrial acid cleaning, acid pickling, acid descaling and oil well acidizing [2]. Due to the aggressiveness of acids, inhibitors are used to reduce the rate of dissolution of metals.

\footnotetext{
* Corresponding author. E-mail address: gurmeet123@yahoo.co.in; ramananda2002@yahoo.co.in
} 
It is reported that nitrogen-containing compounds such as azole derivatives [3-7], imidazolin derivatives [8, 9], alkyl and aryl amines [10-12] perform better in hydrochloric acid. In general, most of the effective and efficient inhibitors in usage are organic compounds having $\pi$ bonds and heteroatoms like nitrogen, sulphur and oxygen atoms, etc., in their structures [13]. The efficiency of an organic compound as a successful inhibitor is mainly dependent on its ability to get adsorbed on the metal surface. 4-acetyl pyridine [14], aliphatic amines [15] such as dimethylamine, ethylamine, diethylamine, butylamine, butyldiethylamine and other derivatives of octylamine inhibit the corrosion of steel in acid solution by donating the unshared pair of electrons from the $\mathrm{N}$ atom and form a surface complex. Alkylene pyridinium compounds inhibit mild steel corrosion in $0.5 \mathrm{M}$ $\mathrm{H}_{2} \mathrm{SO}_{4}$ due to inter-molecular synergism by the introduction of substituents in the pyridine ring [16]. The inhibitive effect of aniline and alkylamine [17], $p$ substituted anilines [18] and $N$-substituted anilines [19] is attributed to the interaction of $\pi$-electron cloud of aromatic ring on iron and steel surface through vacant ' $d$ ' orbital of iron, leading to the formation of co-ordination bond between $\mathrm{Fe}-\mathrm{N}$. The corrosion inhibition property of low molecular weight straight chain amines for steel corrosion has also been studied [20]. Recently, ortho-substituted anilines [21] and polyanilines [22, 23] have also been studied.

In this paper, the inhibition effect of diethanolamine on the corrosion of iron in $0.5 \mathrm{M} \mathrm{H}_{2} \mathrm{SO}_{4}$ is discussed. The structure of diethanolamine can be given as

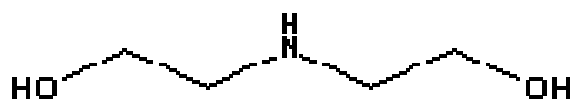

Its inhibitive effect on acid corrosion of mild steel in $0.5 \mathrm{M}$ sulphuric acid was investigated by various corrosion monitoring techniques like galvanostatic polarization studies, potentiostatic polarization studies, scanning electron microscopy (SEM), infrared spectroscopy (IR) and Quantum Chemical Studies. Its inhibitive effect on acid corrosion of mild steel in $0.5 \mathrm{M}$ sulphuric acid at different temperatures was also studied.

\section{Experimental procedure}

An electrochemical cell assembly of three electrodes was used for Tafel polarization and potentiostatic polarization studies. The experiments were conducted using mild steel having the composition: $\mathrm{C}=0.15 \%, \mathrm{Mn}=1.02 \%$, $\mathrm{Si}=0.025 \%, \mathrm{P}=0.025 \%$ and rest being $\mathrm{Fe}$. The test specimens were cut into $1 \mathrm{~cm}$ $\times 1 \mathrm{~cm}$ size with help of shearing machine and edges were smoothened. They were abraded into uniform surfaces with the help of grinding machine by using 150, 320, 400 and 600 grade emery papers. The working electrodes were soldered with insulated copper wire and after proper surface preparation; they were coated thoroughly with epoxy resin keeping surface area of $1 \mathrm{~cm}^{2}$ exposed to corrosive medium. Calomel electrode was used as the reference electrode and platinum wire was used as auxiliary electrode. Polarization measurements were made under thermostatic conditions at $303 \mathrm{~K}, 313 \mathrm{~K}, 323 \mathrm{~K}$ and $333 \mathrm{~K}$. 


\section{Results and discussion}

\section{Galvanostatic polarization studies}

The results of the effect of additive concentrations on mild steel in $0.5 \mathrm{M}$ sulphuric acid are shown in Table 1 and the representative polarization curves at $303 \mathrm{~K}$ are shown in Fig. 1. The corrosion currents were calculated from the extrapolation of the Tafel line up to open circuit potential and the inhibition efficiency was calculated from $\mathrm{I}_{\text {corr }}$ values in the presence and absence of additive [24], i.e.,

$$
\mathrm{I} \%=\left\{\left(\mathrm{I}_{\mathrm{o}}-\mathrm{I}_{\mathrm{i}}\right) / \mathrm{I}_{\mathrm{o}}\right\} \times 100
$$

where $I_{o}$ is the corrosion current without additive and $I_{i}$ the corrosion current with additive.

Table 1. Corrosion parameters of mild steel in $0.5 \mathrm{M} \mathrm{H}_{2} \mathrm{SO}_{4}$ in presence of various concentrations of DEA.

\begin{tabular}{cccccccc}
\hline $\begin{array}{c}\text { Conc } \\
(\mathrm{M})\end{array}$ & $\begin{array}{c}\text { Temp. } \\
(\mathrm{K})\end{array}$ & $\begin{array}{c}-\mathrm{E}_{\text {corr }} \\
(\mathrm{mV})\end{array}$ & $\begin{array}{c}\mathrm{I}_{\text {corr }} \\
\left(\mathrm{mA} / \mathrm{cm}^{2}\right)\end{array}$ & $\begin{array}{c}\mathrm{b}_{\mathrm{c}} \\
(\mathrm{mV} / \mathrm{dec})\end{array}$ & $\begin{array}{c}\mathrm{b}_{\mathrm{a}} \\
(\mathrm{mV} / \mathrm{dec})\end{array}$ & $\theta$ & $(\mathrm{I} \%)$ \\
\hline 0 & 303 & 515 & 3.85 & 45 & 35 & - & - \\
$10^{-3}$ & & 510 & 2.90 & 120 & 80 & 0.887 & 88.7 \\
$10^{-5}$ & & 505 & 3.30 & 100 & 65 & 0.718 & 71.8 \\
$10^{-7}$ & & 535 & 3.50 & 85 & 50 & 0.553 & 55.3 \\
0 & 313 & 517 & 3.95 & 52 & 33 & - & - \\
$10^{-3}$ & & 500 & 3.20 & 127 & 85 & 0.822 & 82.2 \\
$10^{-5}$ & & 465 & 3.45 & 110 & 69 & 0.684 & 68.4 \\
$10^{-7}$ & & 500 & 3.65 & 65 & 44 & 0.498 & 49.8 \\
0 & 323 & 510 & 4.00 & 47 & 30 & - & - \\
$10^{-3}$ & & 490 & 3.33 & 130 & 88 & 0.786 & 78.6 \\
$10^{-5}$ & & 495 & 3.65 & 115 & 72 & 0.553 & 55.3 \\
$10^{-7}$ & & 490 & 3.74 & 75 & 35 & 0.451 & 45.1 \\
0 & 333 & 530 & 4.20 & 45 & 30 & - & - \\
$10^{-3}$ & & 485 & 3.80 & 145 & 94 & 0.602 & 60.2 \\
$10^{-5}$ & & 490 & 3.90 & 120 & 80 & 0.499 & 49.9 \\
$10^{-7}$ & & 502 & 3.97 & 69 & 37 & 0.411 & 41.1 \\
\hline
\end{tabular}

The inhibition efficiency has been found to increase with increase in concentrations of DEA and decrease with the increase in temperature. The result shows high degree of corrosion inhibition at higher concentration. With the increase in temperature, the adsorption tends to weaken resulting in short time lag between adsorption and desorption, thus leading to higher extent of corrosion. At $303 \mathrm{~K}$, the corrosion current density changes from $3.50 \mathrm{~mA} . \mathrm{cm}^{-2}$ to 2.90 $\mathrm{mA} . \mathrm{cm}^{-2}$ as concentration is changed from $10^{-7} \mathrm{M}$ to $10^{-3} \mathrm{M}$ at $303 \mathrm{~K}$, respectively, while this change is from $3.97 \mathrm{~mA} . \mathrm{cm}^{-2}$ to $3.80 \mathrm{~mA} . \mathrm{cm}^{-2}$ for the above inhibitor concentration range at $333 \mathrm{~K}$. Thus it can be seen that the decrease in corrosion current is much more pronounced at lower temperatures than at higher ones. The inhibition efficiency is reduced to $60.2 \%$ at $333 \mathrm{~K}$ as 
compared to $88.7 \%$ at $303 \mathrm{~K}$ for $10^{-3} \mathrm{M}$ DEA. Hence, there is a considerable decrease in the inhibition efficiency with the increase in temperature at fixed concentration. Thus, DEA is an efficient inhibitor. From the Table, this inhibitor shows no appreciable shift of $\mathrm{E}_{\text {corr }}$ towards any direction. It indicates that these inhibitors act as mixed type ones. Tafel cathodic and anodic slope values are found to vary in the regular manner at all the temperatures. The values of cathodic and anodic Tafel slope increase with increase in concentration at a fixed temperature. It is also evident that cathodic and anodic Tafel slope value at fixed concentration increases with increase in temperature. This indicates that the inhibitory effect of DEA may be predominantly due to adsorption of amine (NH-) and hydroxyl (-OH) groups on metal surface.

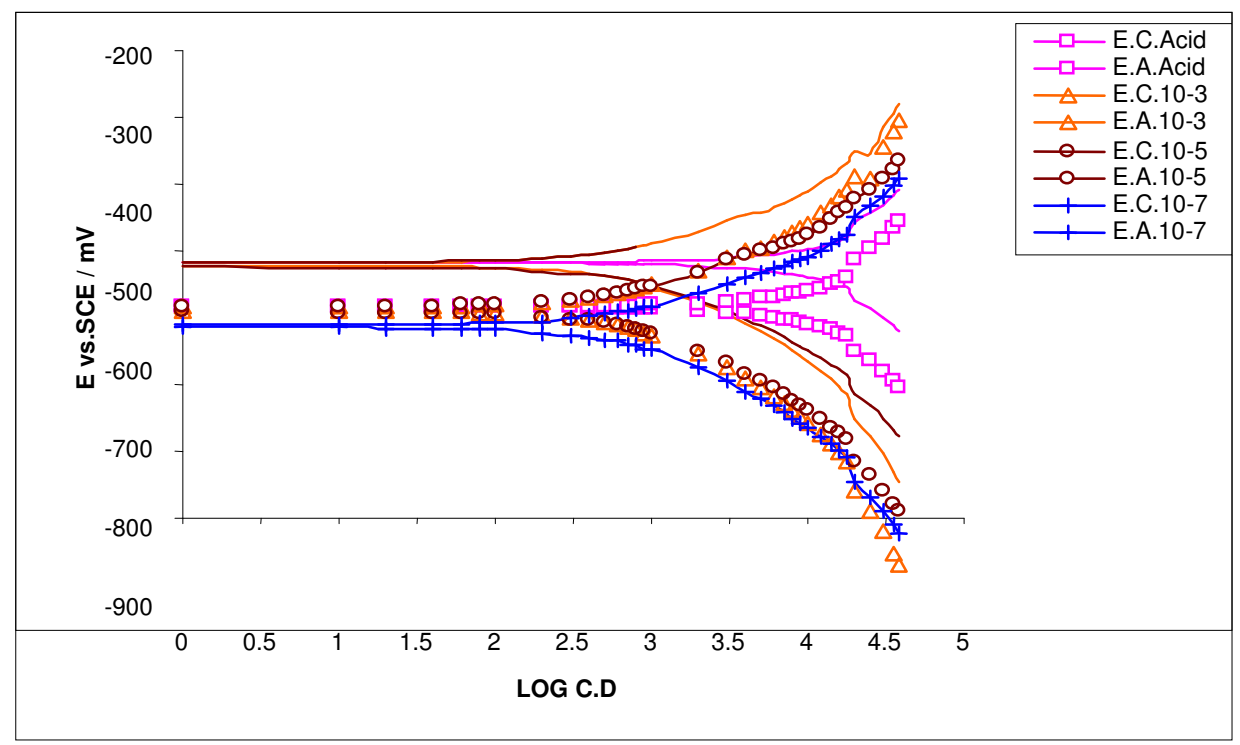

Figure 1. Galvanostatic polarization curve for the corrosion of mild steel in $0.5 \mathrm{M}$ $\mathrm{H}_{2} \mathrm{SO}_{4}$ solution and in the presence of various concentrations of DEA at $303 \mathrm{~K}$.

\section{Potentiostatic polarization studies}

Passivity affects the kinetics of corrosion process because it produces a protective film that acts as a barrier to attack on the metal surface by the environment. Fig. 2 shows the representative potentiostatic polarization curve for the corrosion of mild steel in $0.5 \mathrm{M} \mathrm{H}_{2} \mathrm{SO}_{4}$ solution and in the presence of various concentrations of DEA at $303 \mathrm{~K}$. The effects of DEA have been studied in terms of electrochemical parameters, i.e., critical current density $\left(i_{c}\right)$, passivation potential $\left(E_{p p}\right)$, and passivation current, and are shown in Table $2 . i_{c}$ is found to decrease with increasing concentration. The value of $i_{p}$ decreases from 3.19 $\mathrm{mAcm}^{-2}$ to $0.50 \mathrm{mAcm}^{-2}$ as the concentration of DEA is increased from $10^{-7}$ to $10^{-3} \mathrm{M}$. Passivation range is more in presence of additive than that of pure acid and increases with increase in concentration of DEA. The value of $i_{p}$ is lowered when compared with the dissolution in the absence of additives. The passivation current, $i_{p}$, is found to be lower at higher concentration as compared to lower concentration of DEA. This indicates that DEA passivates the mild steel 
effectively in the higher concentration. These values show that this compound acts as good passivator of mild steel in $0.5 \mathrm{M} \mathrm{H}_{2} \mathrm{SO}_{4}$ solution. The passivity may be due to the formation of complexes of the type $[\mathrm{M}-\mathrm{In}-\mathrm{OH}]_{\mathrm{ads}}$ or $[\mathrm{M}-\mathrm{OH}-\mathrm{In}]_{\mathrm{ads}}$, etc., in solution on the metal surface [25]. The passivation parameters may also be depending on the presence of the already adsorbed anions [26].

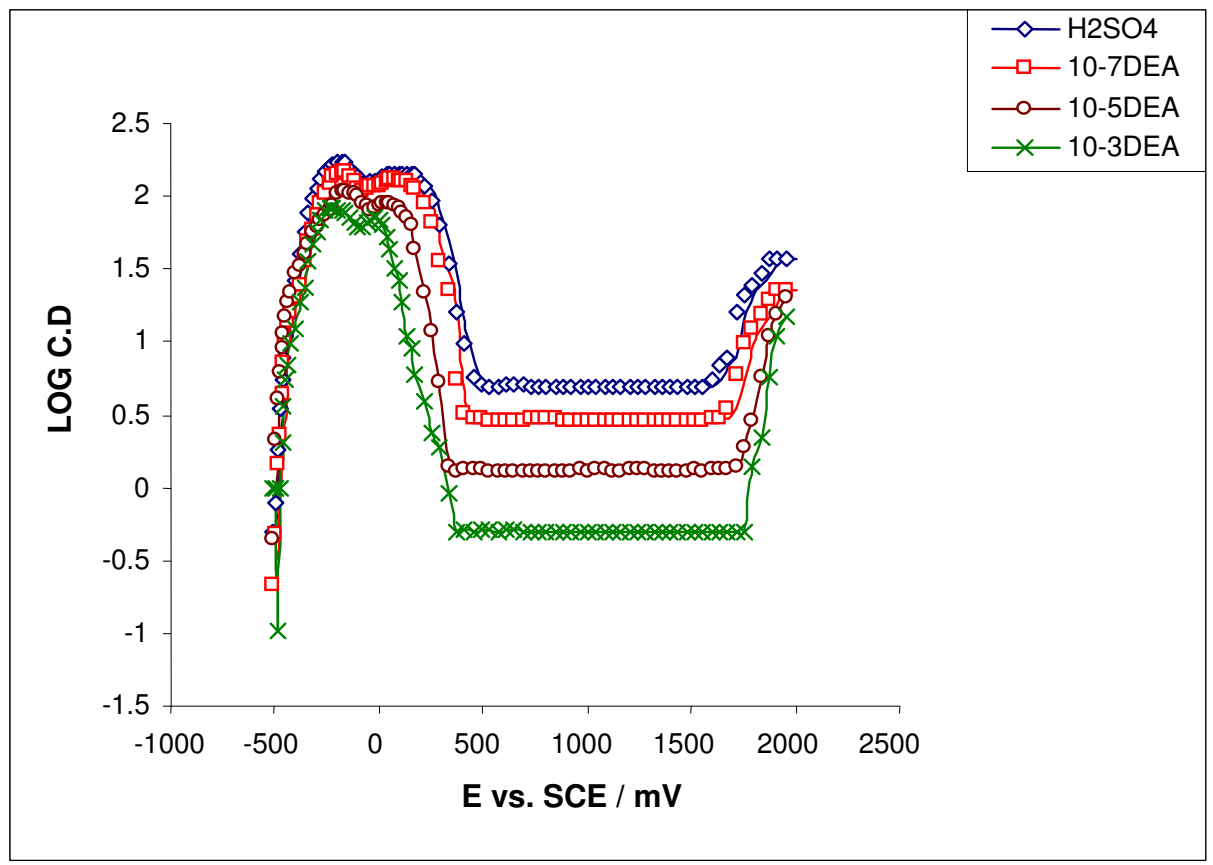

Figure 2. Potentiostatic polarization curve for the corrosion of mild steel in $0.5 \mathrm{M}$ $\mathrm{H}_{2} \mathrm{SO}_{4}$ solution and in the presence of various concentrations of DEA at $303 \mathrm{~K}$.

Table 2. Electrochemical parameters of anodic dissolution of mild steel in $0.5 \mathrm{M} \mathrm{H}_{2} \mathrm{SO}_{4}$ in the presence of inhibitor.

\begin{tabular}{|c|c|c|c|}
\hline Solutions & $\mathrm{i}_{\mathrm{C}}\left(\mathrm{mAcm}^{-2}\right)$ & $\mathrm{i}_{\mathrm{p}}\left(\mathrm{mAcm}{ }^{-2}\right)$ & $\begin{array}{l}E_{P P}(m V) \\
\text { Range }\end{array}$ \\
\hline $0.5 \mathrm{M} \mathrm{H}_{2} \mathrm{SO}_{4}$ & $1.71 \times 10^{2}$ & 5.09 & $520-1600$ \\
\hline $10^{-7} \mathrm{M}$ DEA & $1.45 \times 10^{2}$ & 3.19 & $440-1680$ \\
\hline $10^{-5} \mathrm{M}$ DEA & $1.07 \times 10^{2}$ & 1.39 & $360-1760$ \\
\hline $10^{-3}$ M DEA & $0.83 \times 10^{2}$ & 0.50 & $400-1800$ \\
\hline
\end{tabular}

\section{Temperature kinetics studies}

The adsorption kinetics and the effect of temperature on acid corrosion of metals in the presence and absence of DEA were studied. The corrosion data have been analyzed to determine the surface coverage $(\theta)$ at different temperatures, which can be calculated using the equation,

$$
\theta=(\mathrm{I} \% / 100)
$$

where $I \%$ is the inhibition efficiency. The effective activation of energy $\left(E_{a}\right)$ is calculated from the following equation:

$$
\log \mathrm{I}_{\text {corr }}=\mathrm{B}-\mathrm{E}_{\mathrm{a}} / 2.303 \mathrm{RT}
$$


where $\mathrm{B}$ is a constant and $\mathrm{I}_{\text {corr }}$ is the corrosion current density.

The values of $\mathrm{E}_{\mathrm{a}}$ given in Table 3 indicate that this inhibitor gets physically adsorbed on the mild steel surface. The higher values of effective activation energy $\left(E_{a}\right)$ in the presence of inhibitor as compared to the $E_{a}$ in the absence of inhibitor in sulfuric acid indicates that the inhibitor induces the energy barrier for the corrosion reaction which leads to the decreasing of rate of corrosion of mild steel in the present of inhibitor.

According to O.K. Aiola, B.B. Damaskin [27, 28], the value of activation energy less than $80 \mathrm{~kJ} / \mathrm{mol}$ and even smaller than $5 \mathrm{~kJ} / \mathrm{mol}$ represents physical adsorption. Hence, in the present observation, a considerably lower value of $E_{a}$ in the inhibitor is the indication of inhibitory effect of inhibitor through physical adsorption. The plots of $\log \mathrm{I}_{\text {corr }}$ versus $1 / \mathrm{T}$ show strong correlation coefficient as shown by the values of $\left(\mathrm{R}^{2}\right)$ given in Table 3 .

Since the inhibition by DEA is through physical adsorption, there may be a possibility of DEA forming a multilayer protective coverage on the surface of mild steel.

Table 3. Kinetic parameters of mild steel in $0.5 \mathrm{M} \mathrm{H}_{2} \mathrm{SO}_{4}$ in the presence of the inhibitor.

\begin{tabular}{ccc}
\hline $\begin{array}{c}\text { Conc. } \\
(\mathrm{M})\end{array}$ & $\begin{array}{c}\mathrm{Ea} \\
(\mathrm{kJ} / \mathrm{mole})\end{array}$ & $\begin{array}{c}\mathrm{R}^{2} \\
\left(\mathrm{E}_{\mathrm{a}}\right)\end{array}$ \\
\hline 0 & 2.3125 & 0.9412 \\
$10^{-3}$ & 7.1208 & 0.9623 \\
$10^{-5}$ & 4.6656 & 0.9924 \\
$10^{-7}$ & 3.2415 & 0.9798 \\
\hline
\end{tabular}

Several isotherms like Langmuir isotherm, El-Awady isotherm, Temkin isotherm, Freundlich isotherm, Frumkin isotherm and Flory-Huggins isotherm, etc., were studied. Among all these isotherms, the best-fit adsorption isotherm is the Frumkin adsorption isotherm for adsorption of DEA on mild steel surface with the mean $\mathrm{R}^{2}$ value 0.9989 .

This means that there is an adsorption on a homogenous surface with interaction in the adsorption layer and the negative "a" value suggests that there is a decrease in the adsorption energy that is caused by the repulsive lateral force between the molecules in the adsorbed layer. DEA follows Frumkin adsorption isotherm.

The adsorption on a homogeneous surface with an interaction in the adsorption layer obeys Frumkin's isotherm [29]. The equation of Frumkin isotherm is,

Taking log on both sides, it becomes,

$$
\{\theta /(1-\theta)\} \mathrm{e}^{-2 \mathrm{a} \theta}=\mathrm{KC}
$$

$$
\log \{\theta /(1-\theta) C\}=\log K+2 \mathrm{a} \theta
$$

where ' $a$ ' is the interaction parameter which can be positive or negative. A positive value indicates that the adsorption energy is increased by the lateral 
attraction between the adsorbed molecules and the negative values suggest that there is the presence of the lateral force of repulsion between the molecules in the adsorbed layer. Therefore, DEA after adsorption through amine (NH-) and the hydroxyl groups (OH-) on the metal surface experiences lateral repulsive interactions among the amine (NH-) and the hydroxyl groups $(\mathrm{OH}-)$. This also supplements that the adsorption of this inhibitor occurs via donation of electrons of nitrogen and oxygen atoms to the metal.

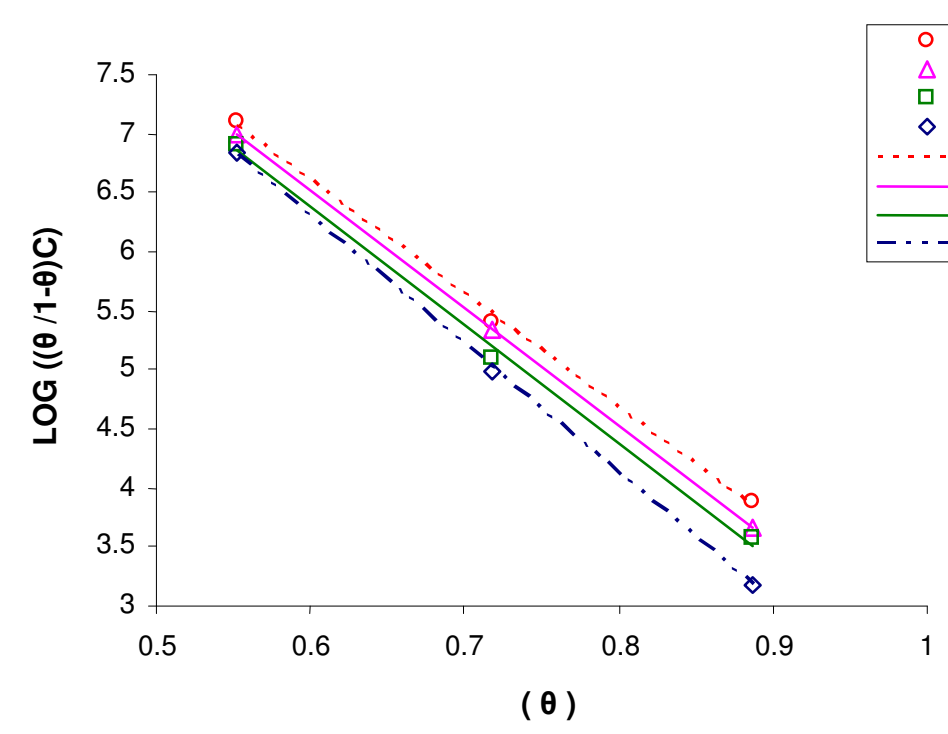

Figure 3. Curve fitting of the plot of $\log \{\theta /(1-\theta) \mathrm{C}\}$ vs. $\theta$ for mild steel in $0.5 \mathrm{M} \mathrm{H}_{2} \mathrm{SO}_{4}$ in the presence of DEA at different temperatures ( Frumkin isotherm).

Table 4. Equilibrium constant and Gibbs free energy values for DEA at various temperatures calculated from Frumkin isotherm.

\begin{tabular}{ccccc}
\hline $\begin{array}{c}\text { Temp. } \\
(\mathrm{K})\end{array}$ & $\mathrm{a}$ & $\mathrm{K}$ & $\mathrm{R}^{2}$ & $\begin{array}{l}\Delta \mathrm{G}_{\mathrm{ads}} \\
(\mathrm{kJ} / \mathrm{mol})\end{array}$ \\
\hline 303 & -4.415 & $2.394 \times 10^{5}$ & 0.9988 & -41.32 \\
313 & -4.985 & $2.708 \times 10^{5}$ & 1.0000 & -43.00 \\
323 & -5.01 & $2.430 \times 10^{5}$ & 0.9967 & -44.08 \\
333 & -5.48 & $3.947 \times 10^{5}$ & 0.9999 & -46.79 \\
\hline
\end{tabular}

From the plots of $\log \{\theta /(1-\theta) \mathrm{C}\}$ vs. $\theta$, shown in Fig. 3, values of $\mathrm{K}$ and "a" are calculated from intercept and slope, respectively. The values of free energy of adsorption $(\Delta \mathrm{G})_{\mathrm{ads}}$, are calculated by using the following equation [30]:

$$
\Delta \mathrm{G}_{\mathrm{ads}}=-\mathrm{RT} \ln 55.5 \mathrm{~K}
$$


The various values are tabulated in the Table 4 . The mean value of $\Delta \mathrm{G}_{\mathrm{ads}}$ for this isotherm is $-43.798 \mathrm{~kJ} / \mathrm{mol}$. The negative value of $\Delta \mathrm{G}_{\mathrm{ads}}$ indicates the spontaneity of the adsorption process and the stability of the adsorbed layer on the mild steel surface. The low $\Delta \mathrm{G}_{\mathrm{ads}}$ value in the present case further confirms physical adsorption. Gibbs free energy values, $\Delta \mathrm{G}_{\text {ads }}$ between $-49 \mathrm{~kJ} / \mathrm{mol}$ and $-58 \mathrm{~kJ} / \mathrm{mol}$ are indicative of chemisorption, according to G. Bereket et al. [31]. The low $\Delta \mathrm{G}_{\text {ads }}$ value in the present case further confirms physical adsorption.

\section{SEM studies}

Scanning electron micrographs of corroded surface of mild steel after immersion in $0.5 \mathrm{M} \mathrm{H}_{2} \mathrm{SO}_{4}$ solution are shown in Fig. 4.1 at the magnification of 5000. A large number of pits and cracks badly corroding the surface of the mild steel coupons are visible.

Fig. 4.2-4.3 show the scanning electron micrographs of mild steel specimens exposed to $0.5 \mathrm{M} \mathrm{H}_{2} \mathrm{SO}_{4}$ in the presence of $10^{-3} \mathrm{M}$ and $10^{-7} \mathrm{M}$ of DEA at magnifications of 5000. In presence of DEA the surface of mild steel is less corroded in $0.5 \mathrm{M}$ sulphuric acid than without it. The inhibitor molecule fully covers the metal surface, giving it a high degree of protection against corrosion, as proved by the absence of pits on the surface. Scanning electron microscopic studies reveal that the extent of corrosion of mild steel decreases with the increase of concentration of the inhibitors. This is in agreement with electrochemical results.

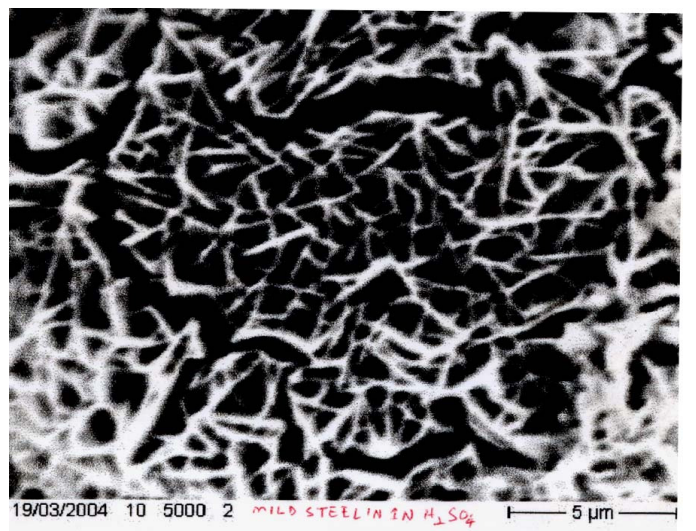

Figure 4.1. SEM of mild steel in $0.5 \mathrm{M}$ $\mathrm{H}_{2} \mathrm{SO}_{4}$ at $5000 \AA \AA$ magnification.

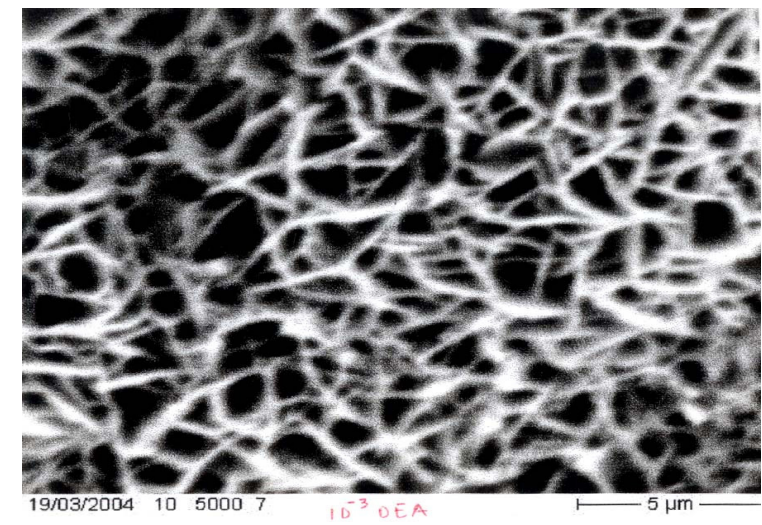

Figure 4.2. SEM of mild steel in $0.5 \mathrm{M}$ $\mathrm{H}_{2} \mathrm{SO}_{4}$ in the presence of $10^{-3} \mathrm{M}$ DEA at 5000 Â magnification.

\section{IR spectroscopy}

IR spectroscopy has been used to investigate the nature and center of adsorption by adsorbing the inhibitor on the silver iodide. An IR spectrum of the pure inhibitor was also traced. On comparing the peaks of adsorbed spectra and pure spectra, it was found that a number of peaks have either disappeared or shifted. This indicates that these inhibitors are adsorbed on the silver iodide surface to certain extent. Since these are adsorbed on the surface, it is anticipated that the 
adsorption of these inhibitors takes place on the mild steel surface as well. The IR spectra of pure DEA are shown in Fig. 5.1. The important peaks of pure and adsorbed DEA are given in Table 6.

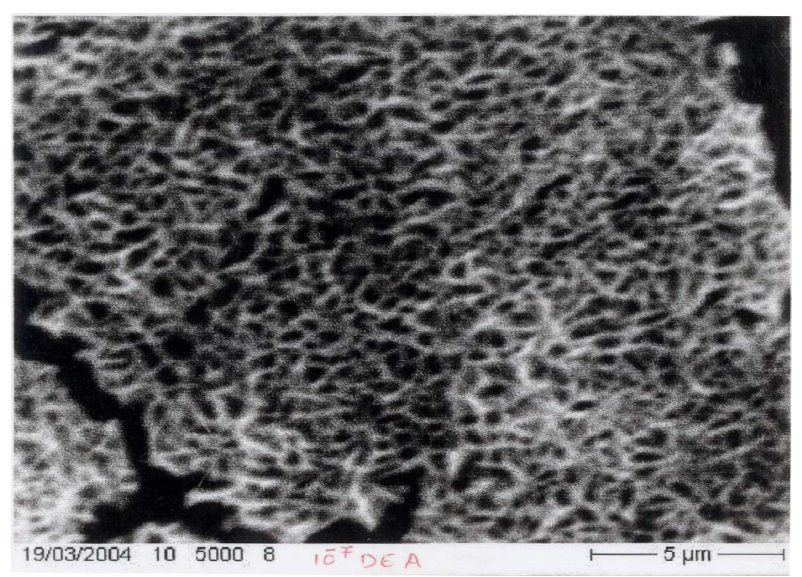

Figure 4.3. $\mathrm{SEM}$ of mild steel in $0.5 \mathrm{M} \mathrm{H}_{2} \mathrm{SO}_{4}$ in the presence of $10^{-7} \mathrm{M}$ DEA at $5000 \AA$ magnification.

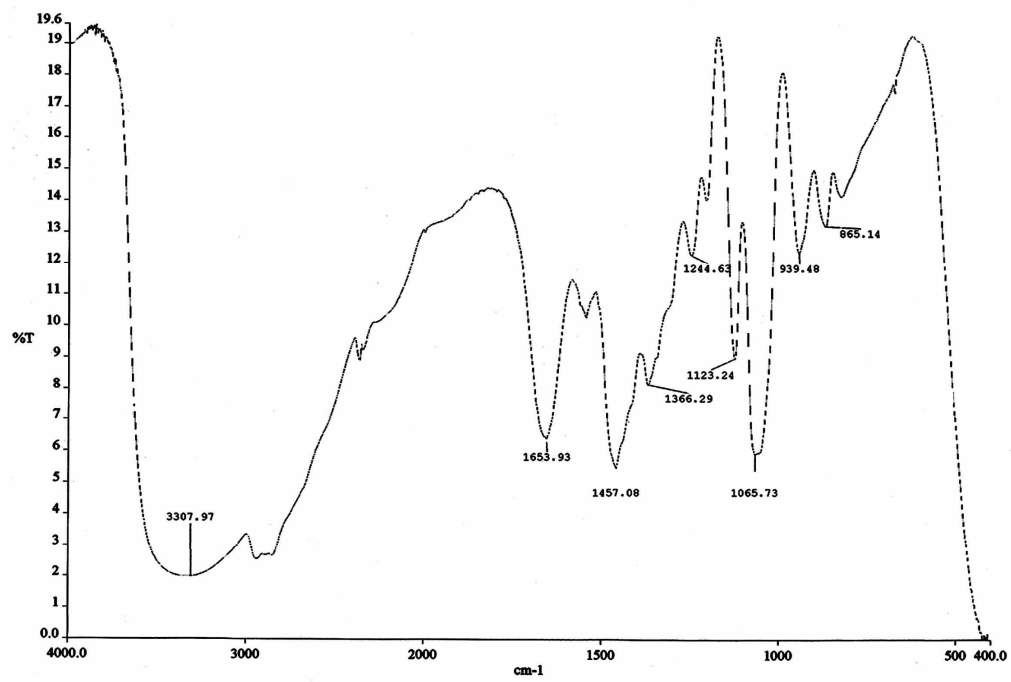

Figure 5.1. FTIR spectra of pure DEA in $\mathrm{KBr}$ medium.

The peak at $3307.97 \mathrm{~cm}^{-1}$ (broad peak) is due to N-H (str) of secondary amine and $\mathrm{O}-\mathrm{H}$ (str) of alcohol including the intermolecular hydrogen bonding. The peaks at $1457.08 \mathrm{~cm}^{-1}$ and $1366.29 \mathrm{~cm}^{-1}$ correspond to $\mathrm{C}-\mathrm{H}$ bending (def) of methylene and the peak at $1244.63 \mathrm{~cm}^{-1}$ is because of $\mathrm{C}-\mathrm{N}$ (str) bond present in the molecule. The peak at $1065.73 \mathrm{~cm}^{-1}$ is due to $\mathrm{O}-\mathrm{H}$ bending (def) and the peak at $1123.24 \mathrm{~cm}^{-1}$ corresponds to $\mathrm{O}-\mathrm{C}$ (str) bond present in the molecule. 
Table 6. Important peaks of pure and adsorbed inhibitors (frequency in $\mathrm{cm}^{-1}$ ).

\begin{tabular}{ccc}
\hline Inhibitor & DEA & DEA on AgI \\
\hline $\mathrm{N}-\mathrm{C}$ (str) & 1244.63 & - \\
$\mathrm{H}-\mathrm{O}$ (str) & 3307.97 & - \\
$\mathrm{N}-\mathrm{H}$ (str) & 3307.97 & - \\
$\mathrm{C}-\mathrm{O}$ (str) & 1123.24 & - \\
$\mathrm{H}-\mathrm{O}$ (def) & 1065.73 & 1057.70 \\
C-H & 1457.08, & 1383.95 \\
(bending) & 1366.29 &
\end{tabular}

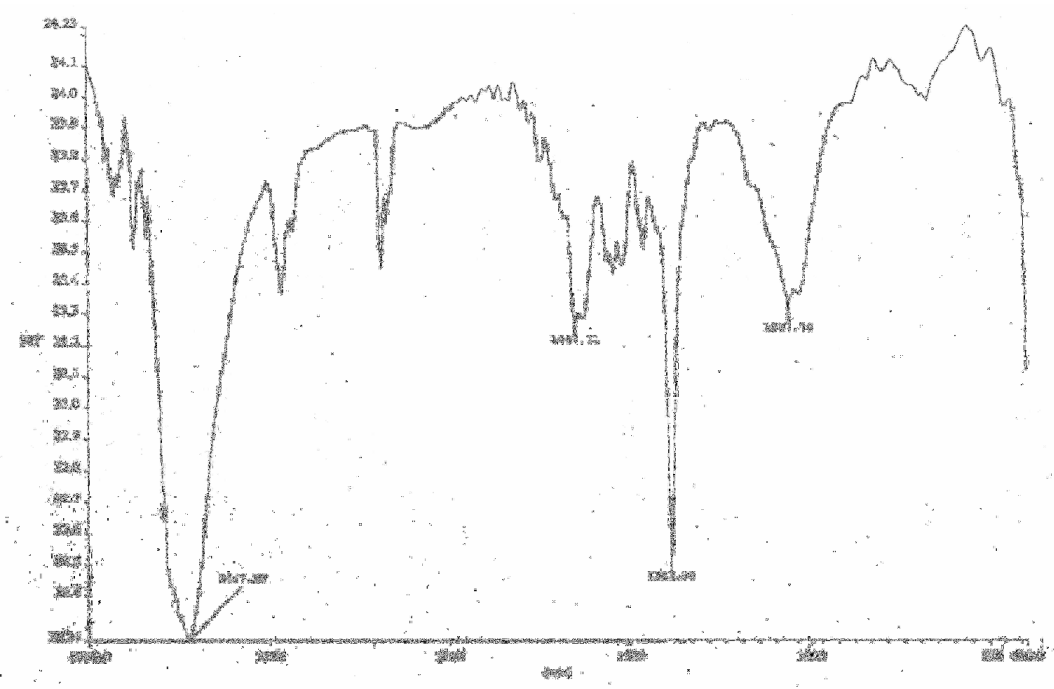

Figure 5.2. FTIR spectra of DEA adsorbed on AgI in KBr medium.

Fig. 5.2 shows the infrared spectra of DEA adsorbed on the silver iodide in $\mathrm{KBr}$ medium. It is evident from the spectra that the peak at $3307.97 \mathrm{~cm}^{-1}$ (broad peak) has disappeared, indicating that nitrogen and oxygen atoms are participating in the adsorption process through their lone pairs and this shows the good adsorption. And the peak at $1457.08 \mathrm{~cm}^{-1}$ has shifted to $1383.95 \mathrm{~cm}^{-1}$, suggesting that it was affected and involved in adsorption, and the peak at $1366.29 \mathrm{~cm}^{-1}$ has also disappeared. The peak at $1244.63 \mathrm{~cm}^{-1}$ has disappeared, confirming that nitrogen atom is adsorbed on the surface of the silver iodide, and the peaks at $1123.24 \mathrm{~cm}^{-1}$ and $1065.73 \mathrm{~cm}^{-1}$ have shifted to the lower frequency, giving a broad peak at $1057.70 \mathrm{~cm}^{-1}$, confirming that oxygen atoms are also effectively involved in the adsorption process.

DEA, as indicated from the spectral data, results in strong adsorption due to donation of lone pair of electrons on oxygen and nitrogen to vacant $d$ orbital of the metal which leads to the formation of metal complexes. 


\section{Quantum studies}

In the light of experimental observation for the choice of good inhibitor acting on metal steel in $0.5 \mathrm{M} \mathrm{H}_{2} \mathrm{SO}_{4}$ the quantum chemical study has been carried out to authenticate the above information at the electronic level.

Table 7. Optimized AM1 parameters for the inhibitors using hyperchem 5.1.

\begin{tabular}{lc}
\hline $\begin{array}{l}\text { Inhibitor } \rightarrow \\
\text { Parameters } \downarrow\end{array}$ & DEA \\
\hline No. of electrons & 44 \\
Energy of HOMO (kJ/mol) & -822.1186 \\
Energy of LUMO (kJ/mol) & -30.0939 \\
Binding energy (kJ/mol) & -140358.0877 \\
Charge on system & 0 \\
Dipole moment (Debye) & 1.683 \\
Charge on N-atom & -0.0909 \\
Charge on O-atoms & $-0.231,-0.194$ \\
Inhibitor efficiency (I\%) & 88.7 \\
at $(303$ K) & \\
\hline
\end{tabular}

The geometry of the molecule has been optimized by AM1 PolakRibiere optimizer with convergence limit $=0.10$ of hyperchem. $5.1[32,33]$.

The quantum chemical calculation parameters are given in the Table 7 . The relation between inhibition efficiency of inhibitor and the quantum chemical calculation parameters like $\mathrm{E}_{\mathrm{HOMO}}$ and $\mathrm{E}_{\mathrm{LUMO}}$, dipole moment, binding energy and the charge on the molecules were investigated.

Fig. 6.1 shows the optimized geometry of DEA as ball and stick model and Fig. 6.2-6.5, show 3-D isosurfaces of total charge densities (HOMO), 3-D isosurfaces of total charge densities (LUMO) and electrostatic potential mapped on to 3-D charge density isosurfaces, and charge density maps for active sites of DEA, respectively. The various optimized parameters are reported in Table7. In figures 6.1-6.5, Navy blue balls represent nitrogen atom, green balls represent hydrogen atoms, blue balls represent the carbon atoms, and red balls represent the oxygen atoms.

The negative binding energy (Table 7) indicates that DEA is very stable and is less prone to be split or broken apart. Fig. 6.1 shows that DEA is not a planar molecule but has less steric hindrance. Therefore, the coverage of the surface may be as uniform as observed for planar molecules.

The HOMO-LUMO energy gap (Table 7) shows that DEA is an efficient inhibitor [34] which is also observed by the experimental inhibitor efficiency at $303 \mathrm{~K}$. The value of dipole moment indicates the possibility of adsorption of the DEA by electron donation in the inhibition process. The negative charges on nitrogen and oxygen atoms also show the possibility of adsorption through the nitrogen atom and oxygen atoms. The highest values of the total charge densities (HOMO) were found in the vicinity of the nitrogen atom (Fig. 6.2) indicating it as most probable adsorption centre [35]. Fig. 6.4 and 6.5 show the presence of 
electron charge density along the hydrocarbon chain and nitrogen and oxygen atoms indicating the possibility of the hydrocarbon chain assisting in the adsorption process of nitrogen and oxygen atoms on the metal surface.

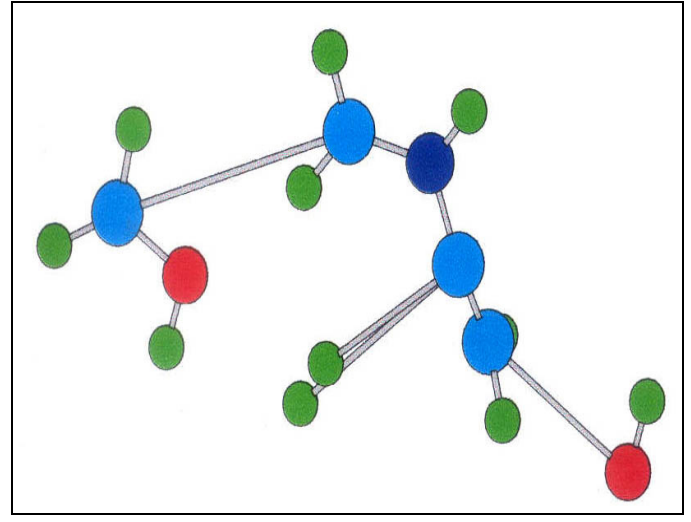

Figure 6.1. Ball and stick model of optimized geometry of DEA.

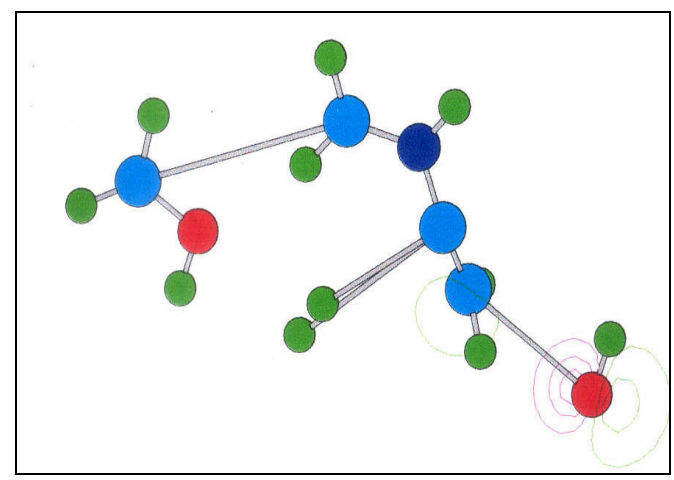

Figure 6.3. 3-D isosurface of total charge density DEA (LUMO).

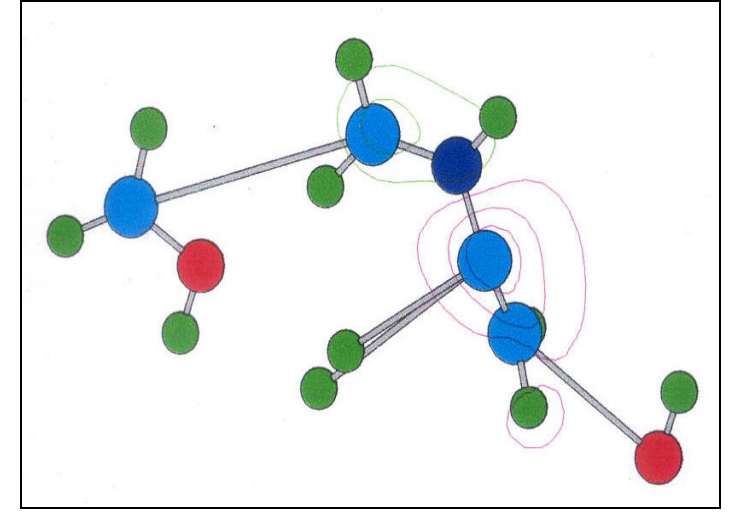

Figure 6.2. 3-D isosurface of total charge density on DEA (HOMO).

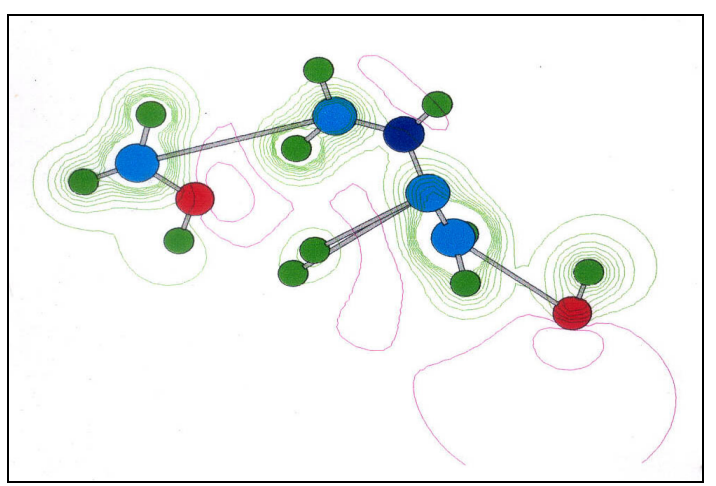

Figure 6.4. Electrostatic potential mapped on to 3-D charge density isosurface of DEA.

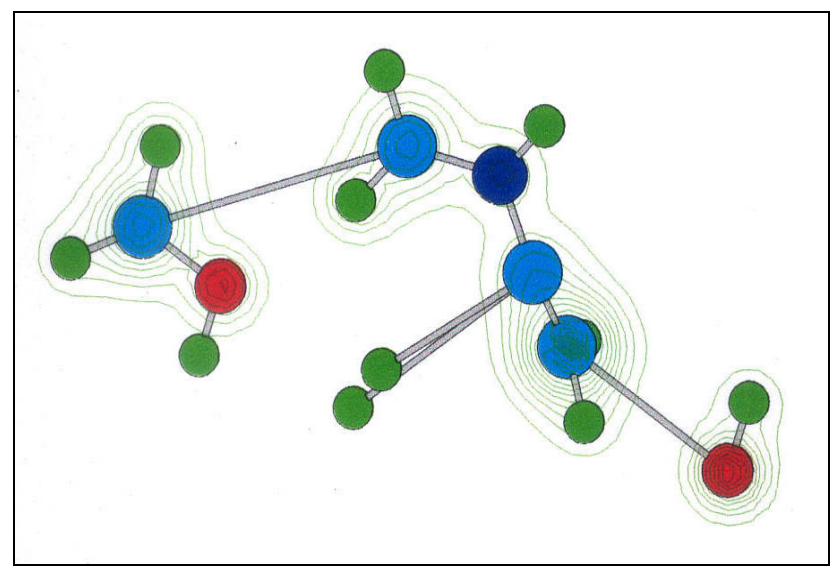

Figure 6.5. Charge density map of DEA for active sites. 


\section{Conclusions}

DEA can be used as inhibitor during acid corrosion of mild steel in $0.5 \mathrm{M}$ sulphuric acid. The corrosion inhibition characteristics have been studied by Tafel polarization, potentiostatic polarization, temperature kinetics at different concentrations and temperatures, IR spectroscopy, SEM and quantum chemicals calculation. It can be concluded that:

1. DEA is an excellent corrosion inhibitor for mild steel in acidic medium.

2. The adsorption of DEA follows the Frumkin adsorption isotherm. The negative value of "a" means that there is repulsion among the adsorbed inhibitor molecule on the metal surface.

3. The adsorption is of physical type suggested by low values of effective activation energy $\left(\mathrm{E}_{\mathrm{a}}\right)$ and free energy of adsorption $\left(\Delta \mathbf{G}_{\mathrm{ads}}\right)$.

4. DEA is a mixed inhibitor inhibiting both cathodic and anodic process to equal extent.

5. The inhibition efficiency increases as concentration of these inhibitors increases.

6. The corrosion is inhibited in the presence of DEA in acid solutions at all temperatures and the inhibition efficiency decreases as temperature increases.

7. The results of infrared spectroscopy (IR) indicate that DEA is adsorbed on mild steel through nitrogen atom and oxygen atoms.

8. The results of SEM are in agreement with the results of electrochemical techniques.

9. Quantum chemical calculations also supplement the results of electrochemical techniques. The negative charge on nitrogen and the highest values of the HOMO densities found in the vicinity of the nitrogen atom indicate that it is the most probable adsorption centre. The involvement of oxygen atoms and $\mathrm{CH}_{2}$ groups in the adsorption is suggested by the negative charge on oxygen atoms and charge density map of DEA for active sites as shown in Fig. 6.4 and electrostatic potential map in Fig. 6.5.

\section{References}

1. S.A. Ali, M.T. Saeed, S.V. Rahman, Corros. Sci. 45 (2003) 253.

2. G. Schmitt, Brit. Corr. J. 19 (1984) 165.

3. M. Elayyachy, M. Elkodadi, A. Aouniti, A. Ramdani, B. Hammouti, F. Malek, A. Elidrissi, Mater. Chem. Phys. 93(2-3) (2005) 281-285.

4. B. Elmehdi, B. Mernari, M. Traisnel, F. Bentiss, M. Lagrenee, Mater. Chem. Phys. 77 (2003) 489

5. A. Popova, M. Christov, T. Deligeorgiev, Corrosion 59 (2003) 756-764.

6. G. Bereket, A. Pinarbasi, C. Ogretir, Anti-Corros. Methods Mater. 51 (2004) 282-293.

7. P. Morales-Gil, G. Negron-Silva, M. Romero-Romo, C. Angeles-Chavez, M. Palomar-Pardave, Electrochim. Acta 49 (2004) 4733-4741.

8. C. Jeyaprabha, S. Sathiyanarayanan, G. Venkatachari, Appl. Surf. Sci. 246(1-3) (2005) 108-116. 
9. V.A. Khanin, N.D. Sokhnenko, A.P. Mel'nik, Zashch. Met. 30(2) (1994) 169 (in Russian).

10. R. Bacskai, A.H. Shroeder, US Patent 4778654 (Cl. 422-7; C 23F11/00) (October 18, 1988); Appl. 926058 (October 31, 1986) 8 pp.

11. G. Perboi, G. Rocchini, International Corrosion Conference Series, NACE (Corrosion Inhibitiors) (1988), 201.

12. W. Jerzykiewicz, M. Kozupa, Przem. Chem. 68(10) (1989) 443 (in Polish).

13. Uhlg's corrosion handbook, R.Winston Revies, Electrochemical Society Series, Ottawa, Ontario, Canada (2000), 1097-1098.

14. J. Vosta, N. Hackerman, Corros. Sci. 30(8-9) (1990) 949.

15. G. Singh, L. Jha, R. Mohapatra, J. Electrochem. Soc. (India) 39(1) (1990) 44.

16. G. Subramanian, K. Balasubramanian, P. Sridhar, Corros. Sci. 30(10) (1990) 1019.

17. H. Luo, Y.C. Guan, K.N. Han, Corrosion 54 (1998) 721.

18. A.A. AbdEl Fattah, R.M. AbdEl Gulil, H.E. Megahed, S.M. AbdEl Haleem, Bull. Electrochem. 7(1) (1991) 18.

19. K. Aramaki, J. Uehara, Zairyo to Kankyo. 41(9) (1992) 612 (in Japanese).

20. R.D. Braun, E.E. Lopez, D.P. Vollmer, Corros. Sci. 34(8) (1993) 1251.

21. K.F. Khaled, N. Hackerman, Electrochim. Acta 48 (2003) 2715.

22. S. Sathiyanarayanan, S.K. Dhawan, D.C. Trivedi, K. Balakrishnan, Corros. Sci. 33 (1992) 1831.

23. S. Sathiyanarayanan, K. Balakrishnan, S.K. Dhawan, D.C. Trivedi, Electrochim. Acta 39 (1994) 831.

24. M.N. Mousa, F.I. Taha, M.M. Gauda, G.M. Singab, Corros. Sci. 16 (1976) 379.

25. H. Ashissi-Sorkhabi, S.A. Nabavi-Amri, Acta Chim. Slov. 47 (2000) 507517.

26. Kalpana Bhrara, Gurmeet Singh, Surf. Engg. 21(3) (2005) 165-171.

27. O.K. Aliola, N.C. Oforka, Corros. Sci. Engg. 3 (2002) 21.

28. B.B. Damaskin, Adsorption of Organic Compounds on Electrodes, Plenum Press, New York, (1971) 221.

29. John O’M. Bockris, Amulya K.N. Reddy, Modern Electrochemistry, Camboa-aldeco (2A), $2^{\text {nd }}$ edition, 938.

30. S.T. Arab, A.M. Al-Turkustani, Port. Electrochim. Acta 24 (2006) 53-69.

31. G. Bereket, A. Yurt, S. Ustun Kandemir, A. Balaban, B. Erk, Aqueous Batteries, $5^{\text {th }}$ Advanced Batteries and Accumulators, 2004.

32. G. Bereket, C. Ogretir, C. Ozsahin, Journal of Molecular Structure: Theochem. 663 (2003) 39-46.

33. M. Lagrenee, B. Mernari, N. Chaibi, M. Traisnel, H. Vezin, F. Bentiss, Corros. Sci. 43(5) (2001) 951-962.

34. S.S. Tahir, Naseem Rauf, J. Chem. Thermodynamics 35 (2003) 2003-2009.

35. M. Özcan, I. Dehri, Progress in Organic Coatings 51(3) (2004) 181-187. 